J Chron Dis 1977, Vol. 30, pp. 781-791. Pergamon Press. Printed in Great Britain

\title{
GENETIC-ENVIRONMENTAL INTERACTIONS IN THE VARIATION OF BLOOD PRESSURE IN TECUMSEH, MICHIGAN
}

\author{
DAvID G. SMITH \\ The Institute for Cancer Research, The Fox Chase Cancer Center, \\ Philadelphia, PA 19111 \\ and \\ Charles F. Sing \\ Department of Human Genetics, University of Michigan Medical School, \\ Ann Arbor, MI 48104
}

(Received in revised form 26 December 1976)

\begin{abstract}
Emigrants and those who die were found to have higher age adjusted systolic BP than non-migrants and emigrants showed higher BP than non-migrants. For two single-locus cases, and their combined two-locus marker case, the BP differences among marker phenotypes were not homogeneous between non-migrants and those who die and between emigrants and those who die. The BP of emigrant marker phenotypes for the non-migrant emigrant contrast varied in the same direction as the BP of marker phenotypes of those who died in the non-migrant-die contrast, but in the former contrast the marker phenotype-subsample interaction was not judged statistically significant by the available samples. This may result from the lack of specificity in the emigrant subsample for comparison which is presumed to have experienced high levels of stress.

Our data suggests that life crises which generate stress exaggerate differences in BP between genotypcs of loci which affect the level or rate of rise of BP. The average effects of both Rh-C and Kell alleles for emigrants resembled that of those who die more closely than that of non-migrants. These results are consistent with an explanation which attributes to stress encountered in life crises a major role in accounting for phenotypic differences in BP. Its effect is to raise BP in certain predisposed genotypes which are marked by dosages of the $\mathrm{c}$ and $\mathrm{k}$ alleles.
\end{abstract}

WhILE the role of genes in determining the variation of blood pressure (BP) is considered by many to be subordinate to the role of environment $[1,2]$, an interaction between genetic and environmental variables has long been postulated [3-5]. Dahl and his colleagues have studied such an interaction controlling BP in rats $\lceil 4,6,7\rceil$, but no such study has been attempted of an unselected human population [8]. It is generally assumed that the predominance of the environmental role over that of genes increases with age [9]. Research into environmental sources of BP variation has usually led to explanations which involve factors associated with stress. This explanation has an analogue in the Mildvan-Strehler model, which predicts the adult mortality distribution with a non-linear decline in the ability 
to accommodate environmental stress as length of exposure to the environment increases [10]. Further, there is evidence that highly mobile individuals experience or perceive excessive emotional stress which can lead to permanently elevated BP [11]. The 'incongruency' hypothesis attributes stress to problems encountered while adapting to unfamiliar environmental situations [12]. Either length or intensity of exposure to stress, then, might affect the pattern of rise in BP. Further, the decision to emigrate itself might reflect problems in adaptation to the social, cultural and psychological milieu in which the individual found himself which may likewise have generated stress. If so, and if the genetic effect upon BP is conditioned by environmental stress, greater differences in BP might be expected between marker phenotypes of certain loci (which are closely linked to loci affecting $\mathrm{BP}$ ) in emigrants than in non-migrants. If a morbid period precedes death, intense emotional stress is likely to occur at the time of life when the ability to cope with stress is minimal. Indeed, stress and raised BP are both considered principal risk factors for coronary heart disease, related disorders and mortality [13, 14]. These differences in BP, then, might also be expected between non-migrants and individuals who die soon after measurement for BP.

These considerations pose the following questions for our analysis: (1) are emigrants and those who die representative samples of the community at large with respect to their $\mathrm{BP},(2)$ are the relative frequencies and mean $\mathrm{BP}$ of the genotypes, as identified by marker loci, homogeneous among the subsamples defined by those who are non-migrants, those who are emigrants and those who die, (3) is the interaction effect on BP between marker phenotype and mobility the same as that between marker phenotype and mortality and (4) does this interaction always result from the exaggeration of differences in mean BP between marker phenotypes of the same loci.

\section{METHODS}

The data for our analysis were the age, BP (systolic and diastolic) and genetic marker phenotypes of the females of an $88 \%$ sample of nearly 10,000 individuals residing in Tecumseh, Michigan between 1959 and 1963. Descriptive data which characterize subdivisions of this sample have been published elsewhere $[15,16]$. The analysis reported here contrasts those who remained within the community from 1959 to at least 1967 with those who did not complete the total of three examinations during this time interval because they had either died or emigrated from the community. The average time intervals between the initial BP measurement and emigration or death for the samples used were both between $5 \frac{1}{2}$ and $6 \mathrm{yr}$. Those females at least $15 \mathrm{yr}$ of age when they participated in the first series of examinations for whom age and both a systolic and diastolic (phase V) BP measurement were recorded and who were typed for all marker loci under consideration define the cohort on which our analyses were conducted. Those above the age of 15 were chosen for the analysis for four reasons: (1) a portion of those below age 15 at the first series of examinations was not asked to return for the third series, (2) most emigrants under age 15 are reasoned to have left in nuclear family units and are thus not genetically independent of other emigrants; thus emigrants, for this reason alone, represent a non-random phenotypic sample from the original cohort [15], (3) the BP of those below $15 \mathrm{yr}$ of age is less likely 
than that of adults to reflect any effects of emotional stress preceding emigration or death and (4) this restriction yields subsamples for analysis whose members' BP scores fall, on the average, within the critical range where increases in BP are known to occur most rapidly [2] and, hence, genotypic differences in BP should be more easily detected.

Since statistical analyses were conducted only upon data collected during the first examination period, the change in an individual's BP over time cannot affect the contrasts to be made here. BP measurements made in subsequent series of examinations were used only to establish the continuation or termination of residency of an individual in the community; errors in ascertainment can affect our results only where a doctor inadvertently failed to take a BP reading or where a subject refused to return for reexamination. Our subsample of emigrants is biased by less than $5 \%$ of those examined at the first series of examinations who refused examination in either of the two subsequent examinations. Definitions of terms to be used hereafter are as follows:

case-the particular measure employed, systolic or diastolic, contrast - a comparison of two different subsamples of a particular case, marker case-a contrast involving a particular one or two-locus marker phenotype.

This analysis involved all possible pairwise contrasts between the three subsamples: Non-migrants vs emigrants, non-migrants vs those who died and emigrants vs those who died. Of 14 marker loci analyzed in a previous study of those emigrating and those dying between the first and second series of examinations, three were implicated as possible candidates for involvement in a genotypeenvironment interaction effect on BP in females but not in males. They were the codominant markers, MN, and Kell, and one dominant marker system, Duffy [16]. A third codominant marker for females (but not for males), Rh-C, was later implicated when a similar analysis of those emigrating and dying between the second and third series of examinations was conducted. The smaller size of the two separate but non-independent sets of data prevented the analysis of two-locus phenotype associations with BP and the identification of all components of variation in BP. In these preliminary analyses Kell, Duffy and $\mathrm{MN}$ marker phenotypes were found to be associated with the diastolic BP while Kell and $\mathrm{Rh}-\mathrm{C}$ were associated with systolic pressures. This study is meant to analyze the nature of these effects, with regard to the questions cited above, in greater depth than was possible in the earlier study. As males were not implicated in preliminary analyses, they are not a part of this study.

Since one Kell phenotype is rare, it was treated in the analyses as a two-phenotype dominant system the same as Duffy. An analysis of the BP sum of squares by multiple linear regression was conducted to determine if the variation of mean BP among marker phenotypes at these loci was homogeneous between the two subsamples of each contrast. The gondness-of-fit of the data to a linear regression model based on a complete set of indicators was compared to the model based on a reduced set (excluding the subsample by marker phenotype interaction term(s)). For the linear regression of BP on marker phenotypes the marker phenotypes were assigned numerical scale values of -1 or +1 for the dominant marker cases and $2 v, v-u$ and $-2 u$ for codominant marker (MN and $\mathrm{Rh}-\mathrm{C})$ cases where 
$u=\mathrm{f}_{(\mathrm{AA})}+\mathrm{f}_{(\mathrm{Aa})} / 2$ and $v=1-u$. For codominant marker cases an orthogonal quadratic scale was included as an independent variable for computing the sum of squares due to deviations from additivity among alleles. The scale values were $1 / f_{(A A)},-2 / f_{(A a)}$ and $1 / f_{(a a)}$ for AA, Aa and aa respectively. Each subsample, for each marker case, was arbitrarily assigned a value of either 1 or 2 for the regression. Although higher order polynomials of age explain additional variation in BP, about $95 \%$ of the sum of squares removed by fitting a cubic regression was removed by the linear term alone. Hence, for convenience of analysis, only the linear age relationship was considered. For the systolic and diastolic female cases, the linear age regression removed 20 and $38 \%$ of the total BP sum of squares. The linear age by subsample interaction was included as an independent variable in the regression, since, if significant, any difference between subsamples in variability of BP among marker phenotypes could be biased by the non-random distribution of ages between the subsamples of the marker case. The sum of squares due to the interaction of subsample and marker phenotype effects was computed using a linear phenotype by subsample scale for dominant marker systems and using both the linear by subsample and the quadratic by subsample scales for the codominant marker systems. A variance ratio $(F)$ was then used to test the marker phenotype by subsample interaction effects. It is a function of the difference in sum of squares removed from the data by the complete $\left(\mathrm{SSR}_{\mathrm{c}}\right)$ and the reduced $\left(\mathrm{SSR}_{\mathrm{r}}\right)$ models:

$$
\frac{\left(\mathrm{SSR}_{\mathrm{c}}-\mathrm{SSR}_{\mathrm{r}}\right) / K}{\mathrm{MSE}_{\mathrm{c}}}
$$

is distributed as an $F$ statistic with numerator degrees-of-freedom, $K$, appropriate for the test and denominator degrees-of-freedom associated with the residual mean square error, $\mathrm{MSE}_{\mathrm{c}}[17]$.

While most non-migrants were typed for all four marker phenotypes, considerably fewer (about 15\%) of those who were emigrants were typed prior to emigration. It is, then, possible that sampling errors might have altered the phenotype frequency distributions of emigrants. If such differences have occurred for markers identifying loci affecting BP, the difference in mean BP between emigrants and other subsamples may be due to frequency differences between the subsamples. The contingency chi-square was used to test the hypothesis of homogeneity of phenotype frequencies between subsamples for each locus.

Next, each of the six possible pairs of the four marker systems was analyzed scparately. For these two-locus marker cases, the phenotypic variance was subdivided into marker phenotype, subsample and marker phenotype by subsample interaction effects. For marker phenotype effects allowance was made, where appropriate, for an additive portion due to average effects of alleles at each of the two loci (linear terms), deviations from linearity due to dominance (quadratic terms) at each codominant locus and epistatic effects (where appropriate, linear by linear, linear by quadratic and quadratic by quadratic). These independent variables representing marker phenotype effects were taken to be the orthogonal scales derived by Cockerham [18] for partitioning the genetic variance attributable to independent segregation of two codominant alleles at each of two loci. Separate interaction variables represented by the product of each of these genetic scales 
with the scale representing the subsample effects were then considered. Significance of the marker phenotype by subsample effect was tested with the $F$ ratio as before with the appropriate numerator degrees-of-freedom for the difference in the sum of squares (three for the Duffy-Kell contrast, five for all dominant by codominant marker cases and eight for the $\mathrm{MN}-\mathrm{Rh}-\mathrm{C}$ marker case). As for single locus analyses, Chi-square tests for heterogeneity of two-locus phenotype frequencies between subsamples of each contrast preceded the regression analysis.

Marker cases where the relative frequencies, but not the adjusted mean BP, of the marker phenotypes are homogeneous between subsamples were interpreted as evidence for a genotype by environment interaction effect. For all marker cases involved in a statistically significant interaction, the regression equations were used to calculate age adjusted mean BP for each marker phenotype of each subsample. Variability among marker phenotypes in each of the two subsamples of these marker cases was then analyzed by the one-way analysis of variance and Scheffe's method of multiple comparisons [17] utilizing the $\mathrm{MSE}_{\mathrm{c}}$ estimated by the analysis for interaction.

\section{RESULTS}

When BP was adjusted for age and age by subsample effects, those who died had statistically greater systolic and diastolic BP means than both non-migrants and emigrants $(P \leqslant 0.001)$. Emigrants had a statistically greater mean systolic (but not diastolic) BP than non-migrants $(P \leqslant 0.05)$. Adjusted systolic means pooled for all genotypes of each subsample in each of the three contrasts are given in Table 1 with the presentation of data on markers involved in a genotype by environment interaction.

Two of the four marker systems considered, $\mathrm{Rh}-\mathrm{C}$ and Kell, gave statistically significant single-locus phenotype by subsample interactions but only for systolic BP. The variance ratios and significance levels for the marker cases involving these systems are presented in Table 2 . No single-locus marker case gave a significant marker phenotype by subsample interaction for the non-migrant-emigrant contrast using a 0.05 size test. The Rh-C and Kell loci gave statistically significant linear marker phenotype by subsample interaction for the non-migrant-die contrast at the 0.005 and 0.01 levels of probability respectively and for the emigrant-die contrasts at the 0.05 level of probability.

For the six two-locus marker cases considered, only the linear by linear by subsample component of interaction for the Rh-C-Kell marker case was statistically significant for any contrast. This effect was detected for both the non-migrant-die and emigrant-die contrasts $(P \leqslant 0.005)$. As in the single locus marker cases, in no instance was diastolic BP involved in a significant interaction.

Table 2 summarizes two important results of the regression analysis. First, the linear relationship among BP means for phenotypes of both Rh-C and Kell differed hetween those who die on the one hand and both emigrants and non-migrants on the other. Secondly, the combination of the linear effects of these two loci also differed between the subsamples of these two contrasts.

Chi-square tests for heterogeneity of phenotype frequencies between all pairs of subsamples contrasted were non-significant for all one-locus tests and were significant for only a single two-locus contrast. Since the significant test $(P \leqslant 0.05)$ 


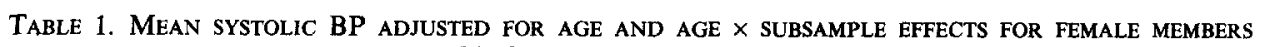
OF EACH OF THE Rh-C $\times$ Kell TWO-LOCUS PHENOTYPE CLASSES $\dagger$

\begin{tabular}{|c|c|c|c|c|c|c|c|c|c|}
\hline & Subsample & $\mathrm{CC}$ & $\mathrm{N}$ & $\mathrm{Cc}$ & $\mathbf{N}$ & $\mathrm{cc}$ & $\mathrm{N}$ & mean & $\mathrm{N}$ \\
\hline \multicolumn{10}{|c|}{ Non-migrants (N) vs emigrants (E) } \\
\hline \multirow[t]{2}{*}{ kk } & $\mathbf{N}$ & 133.6 & 195 & 134.0 & 582 & 132.3 & 347 & 133.4 & 1124 \\
\hline & E & (133.9) & 85 & (134.6) & 239 & (136.8) & 180 & $(135.3)$ & 504 \\
\hline \multirow[t]{2}{*}{ Kk } & $\mathrm{N}$ & 132.2 & 21 & 134.6 & 41 & 127.3 & 27 & 131.8 & 89 \\
\hline & E & (127.4) & 8 & $(135.5)$ & 21 & (126.7) & 17 & (130.8) & 46 \\
\hline \multirow[t]{2}{*}{ Mean } & $\mathrm{N}$ & 133.6 & 216 & 134.1 & 623 & 131.9 & 374 & 133.3 & 1213 \\
\hline & $\mathrm{E}$ & (133.4) & 93 & $(134.8)$ & 260 & $(136.0)$ & 197 & $(134.9)$ & 550 \\
\hline \multicolumn{10}{|c|}{ Non-migrants $(\mathrm{N})$ vs die (D) } \\
\hline \multirow[t]{2}{*}{$\mathrm{kk}$} & $\mathrm{N}$ & 133.3 & 195 & 134.0 & 582 & 131.9 & 347 & 133.2 & 1124 \\
\hline & D & (159.1) & 10 & $(176.0)$ & 40 & (181.8) & 24 & $(175.6)$ & 74 \\
\hline \multirow[t]{2}{*}{ Kk } & $\mathrm{N}$ & 133.1 & 21 & 135.4 & 41 & 127.2 & 27 & 131.7 & 89 \\
\hline & $\mathrm{D}$ & $(-)$ & 0 & $(136.4)$ & 5 & $(174.2)$ & 6 & $(157.0)$ & 11 \\
\hline \multirow[t]{2}{*}{ Mean } & $\mathbf{N}$ & 133.1 & 216 & 134.1 & 623 & 131.5 & 374 & 133.2 & 1213 \\
\hline & D & $(159.3)$ & 10 & $(171.8)$ & 45 & $(180.5)$ & 30 & (173.2) & 85 \\
\hline \multicolumn{10}{|c|}{ Emigrants (E) vs die (D) } \\
\hline \multirow[t]{2}{*}{$\mathrm{kk}$} & $\mathrm{E}$ & 131.2 & 85 & 133.0 & 239 & 134.1 & 180 & 133.1 & 504 \\
\hline & D & (161.1) & 10 & $(178.0)$ & 40 & (184.6) & 24 & $(177.8)$ & 74 \\
\hline \multirow[t]{2}{*}{ Kk } & E & 122.9 & 8 & 133.8 & 21 & 122.7 & 17 & 127.8 & 46 \\
\hline & D & $(-)$ & 0 & (139.8) & 5 & (176.7) & 6 & $(160.0)$ & 11 \\
\hline \multirow[t]{2}{*}{ Mean } & $\mathrm{F}$ & 130.5 & 93 & 133.1 & 260 & 133.1 & 197 & 132.6 & 550 \\
\hline & D & (161.1) & 10 & (173.7) & 45 & $(183.0)$ & 30 & $(175.5)$ & 85 \\
\hline
\end{tabular}

$\dagger$ A dash indicates an empty cell. N, E and D refer, respectively, to the subsamples of non-migrants, emigrants and those who died. In each of the three contrasts BP values for the group presumed to have experienced the greater stress are given in parentheses.

involved the $\mathrm{MN}-\mathrm{Rh}-\mathrm{C}$ marker case for the non-migrant-emigrant contrast, differences in phenotype frequency distributions were not involved in the interpretation of the regression analysis of Rh-C and Kell presented here.

For both loci the significant linear by subsample intcraction is associated with greater differences among marker phenotypes for those who die. These differences are greatest for those who die, less so for emigrants and least for non-migrants.

For the Kell one-locus marker case the ranking of the phenotype means is the same for all three subsamples ( $\mathrm{kk}$ greater than $\mathrm{Kk}$ ) but only for those who die, in their contrast with both non-migrants and emigrants, do the means differ significantly $(P \leqslant 0.005$ and 0.01 , respectively). For the $\mathrm{Rh}-\mathrm{C}$ marker case the ranking of the BP of marker phenotypes is similar for emigrants and those who died (the mean BP increasing with the dosage of c). For non-migrants the hcterozygote has the highest BP and cc the lowest. In both contrasts involving those who died the variation in BP among phenotypes was significant only for those who died. The cc marker phenotype has significantly higher BP than the $\mathrm{CC}$ marker phenotype ( $P \leqslant 0.025$ for both contrasts).

The tests of differences among the BP means of two-locus marker phenotypes in both contrasts involving those who died were statistically significant only in the subsample who died. Of the ten pair-wise tests between BP of phenotypes all statistically significant differences involved the double heterozygote CcKk. The Cckk, cckk, and ccKk phenotypes of those who died had significantly higher BP than $\operatorname{CcKk}(P \leqslant 0.005,0.001$ and 0.05 , respectively) in the non-migrant-die contrast 
Table 2. The analysis of Variance of Female systolic BP due to marker Phenotype|| (Genotype, G) AND MARKER PHENOTYPE (G) $\times$ SUBSAMPLE (ENVIRONMENT, E) INTERACTION

\begin{tabular}{|c|c|c|c|c|c|c|}
\hline \multirow[b]{3}{*}{ Locus } & \multirow[b]{3}{*}{ Source } & \multirow[b]{3}{*}{$d f$} & \multicolumn{4}{|c|}{ Contrasts $\dagger$} \\
\hline & & & \multicolumn{2}{|c|}{ Non-migrant vs die } & \multicolumn{2}{|c|}{ Emigrant vs die } \\
\hline & & & $F$ & $\begin{array}{l}\text { Significance } \\
\text { level }\end{array}$ & $F$ & $\begin{array}{l}\text { Significance } \\
\text { level }\end{array}$ \\
\hline $\mathrm{Rh}-\mathrm{C}$ & $\begin{array}{l}\text { Genotype }(G) \\
\quad \text { linear } \\
\text { quadratic } \\
G \times E \\
\quad \text { linear } \times E \\
\text { quadratic } \times E\end{array}$ & $\begin{array}{l}2 \\
1 \\
1 \\
2 \\
1 \\
1\end{array}$ & $\begin{array}{l}0.78 \\
0.34 \\
1.22 \\
4.21 \\
8.39 \\
0.03\end{array}$ & $\begin{array}{c}\text { N.S. } \\
\text { N.S. } \\
\text { N.S. } \\
* \\
s \\
\text { N.S. }\end{array}$ & $\begin{array}{l}1.55 \\
3.06 \\
0.03 \\
2.17 \\
4.20 \\
0.14\end{array}$ & $\begin{array}{l}\text { N.S. } \\
\text { N.S. } \\
\text { N.S. } \\
\text { N.S. } \\
* \\
\text { N.S. }\end{array}$ \\
\hline Kell & $\begin{array}{l}\text { Genotype (linear) } \\
G \times E(\text { linear } \times E)\end{array}$ & $\begin{array}{l}1 \\
1\end{array}$ & $\begin{array}{l}2.53 \\
7.51\end{array}$ & $\begin{array}{c}\text { N.S } \\
\ddagger\end{array}$ & $\begin{array}{l}6.38 \\
4.43\end{array}$ & 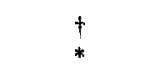 \\
\hline Rh-C-Kell & $\begin{array}{l}\text { Genotype } \\
\mathrm{G} \times \mathrm{G} \\
\text { linear } \times \text { linear } \\
\text { linear } \times \text { quadratic } \\
\mathrm{G} \times \mathrm{E} \\
\mathrm{G} \times \mathrm{G} \times \mathrm{E} \\
\text { linear } \times \text { linear } \times \mathrm{E} \\
\text { linear } \times \text { quadratic } \times \mathrm{E}\end{array}$ & $\begin{array}{l}5 \\
2 \\
1 \\
1 \\
5 \\
2 \\
1 \\
1\end{array}$ & $\begin{array}{l}0.89 \\
0.23 \\
0.34 \\
0.13 \\
5.52 \\
4.33 \\
8.70 \\
0.00\end{array}$ & $\begin{array}{l}\text { N.S. } \\
\text { N.S. } \\
\text { N.S. } \\
\text { N.S. } \\
\text { N.S. } \\
\dagger \\
\text { N.S. } \\
\text { N.S. }\end{array}$ & $\begin{array}{l}1.96 \\
0.06 \\
0.12 \\
0.00 \\
4.52 \\
5.39 \\
9.36 \\
0.00\end{array}$ & $\begin{array}{l}\text { N.S. } \\
\text { N.S. } \\
\text { N.S. } \\
\text { N.S. } \\
\text { N.S. } \\
* \\
. \\
\text { N.S. }\end{array}$ \\
\hline
\end{tabular}

$*, \dagger, \ddagger$ and $\$=$ statistical significance at $P \leqslant 0.05,0.025,0.01$ and 0.005 , respectively.

l| The MSE for the complete model (see text) was used to test, with the $F$ ratio, the marker phenotype effects.

while Cckk and cckk phenotypes had significantly higher pressure than CcKk $(P \leqslant 0.01$ and 0.001 , respectively) in the emigrant-die contrast.

For the two-locus case the ccKk marker phenotype is of lowest pressure for both emigrants and non-migrants but not for those who die. The emigrant marker phenotype with the highest BP, cckk, also has the highest BP anong those who die yet not among non-migrants. The genotype showing the highest BP among non-migrants, CcKk, had the lowest BP among those who died. This failure of the double heterozygote to show a rise in BP in the die group while the marginal locus means for $\mathrm{Cc}$ and $\mathrm{Kk}$ rise is the linear by linear genotype effect detected by the regression analysis.

Since this double heterozygote class numbers only five individuals it seemed critical to determine that they were not closely related, that the adjustments had not led to a misrepresentation of their BP and that no single outlyer among the five was totally responsible for the low mean BP. All five were found to be unrelated and, at a mean age of 76.3, their mean unadjusted systolic BP, 131.6, was about $2 \mathrm{mmHg}$ lower than that of the overall non-migrant population whose mean age is almost half that of this CcKk genotype class. When one of these five, the oldest yet with the lowest systolic and diastolic BP, is excluded from the group, the mean systolic pressure, at mean age 73.3 , is only 139 , still over $25 \mathrm{mmHg}$ lower than that of the entire subsample of deaths. That the corresponding mean diastolic pressure of 87 for the four, however, is only slightly $(2 \mathrm{mmHg})$ below that of the entire subsample of deaths is consistent with our failure to identify a genetic-environment interaction in variation of diastolic BP. 


\section{DISCUSSION}

Two basic assumptions underlie our analyses and are important to the interpretation of our results: (1) genes exist whose effect upon the level of BP can be detected by marker phenotype analyses; and (2) BP measurements for the majority of those who died or emigrated before the end of the third examination period were taken soon enough before the events of death or emigration to fall within a period during which greater than average levels of stress associated with the event were being experienced.

Support for the first assumption is well documented. While the mode of inheritance of susceptibility to hypertension remains enigmatic, the multifactorial hypothesis is favored by most $[2,3,8]$. Once identified, any serologically defined markers lying near one or more of these hypothesized genes can be used to detect the effects of such genes. In a similar manner the serologically defined histocompatibility [HLA] antigens serve as markers for the Ir genes, on the sixth human chromosome, which regulate immune responses [19]. Thus, some HLA antigens have been found associated with immune response deficiencies such as delayed hypersensitivity and impaired complement activity [20].

With regard to the second assumption it is reasoned that the period preceding both emigration and death, during which BP for our data was recorded, constitute two major life crises. If such crises generate emotional stress, as seems likely, and stress contributes to a rise in BP, those who die or emigrate would then be expected to register higher BP than living non-migrants. While this may be true only in cases where stress and resulting cardiovascular responses related to subsequent emigration or death had begun by the first examination period, the number of these cases might well be large enough such that the average subsample BP values for the two groups still exceed those of non-migrants. Our analysis of a female data set has indeed shown that both emigrants and those who die have statistically significantly higher systolic BP than non-migrants.

It has often been claimed that highly mobile individuals may perceive or experience greater stress while adapting to their immediate social, cultural and physical environment $[11,12]$. Cultural, social and economic mobility, all of which often precede emigration, are associated with raised BP [21-25] and variance in BP [26]. Experimentally induced emotional stress can temporarily raise systolic BP of otherwise healthy patients by $25 \mathrm{mmHg}[27,28]$. Other evidence indicates that a number of periodic stress episodes causing repeated contraction of peripheral arterioles might induce hypertrophy, the narrowing of vessel walls which results causing permanently raised BP $[29,30]$. That correlations between emotional lability scores on MMPI tests and BP lability are statistically significant [31] supports this thesis. If the inability to adapt to social or economic conditions generates emotional stress, this may represent a sufficient cause of both raised BP and emigration for the majority of the emigrant subsample who are true emigrants.

The results of both our preliminary analyses $[15,16]$ and those reported here imply that females, but not males, are involved in an interaction between stress and specific one- and two-locus marker phenotypes in determining systolic, but not diastolic, BP. That systolic, but not diastolic, BP is involved is consistcnt with previous research on the hemodynamics of hypertension. While BP elevations can occur in either the systolic or diastolic phases or in both, it is thought that 
rises in systolic BP more often refiect rises in cardiac output while rises in diastolic pressure reflect changes in total peripheral resistance of arterioles [32]. In the labile phases of hypertension which precede the onset of permanently elevated $\mathrm{BP}$ (that phase which is analogous to the period preceding the event of emigration or death of our sanple members), periodic elevations in BP have been found to be associated with high cardiac output but with normal total peripheral resistance [33]. We should expect, then, that during the years preceding the event of death or emigration any transient hypertension resulting from increasing emotional stress should be registered in elevated systolic but almost normal diastolic BP. This was, in fact, supported by our data. Assuming that some form of stress is required for an inherited predisposition to lead to high $\mathrm{BP}$, the failure for our preliminary analyses to identify interaction for males was consistent with the literature on sex-specific differences in hemodynamic response to emotional stress. Gutman and Bensen [34] have reviewed the literature indicating that prehypertensive females are less adaptable in stressful situations and are 'more likely to exhibit the autonomic nervous system concomitants of emotion, including repetitive rises of BP.'

If genes are involved in the determination of BP levels or rates of increase in BP, the mean BP of marker phenotypes closely linked to genes affecting BP of both emigrants and those who die should differ more than that of non-migrants. For any locus affecting BP, marker phenotypes which are less resistant to stress which can elevate pressure should exhibit a rise in BP when and if exposed to stress while marker phenotypes identifying genotypes more successful in coping hemodynamically with increased stress should experience little rise in pressure. It has long been recognized that while pressures of some individuals begin to rise rapidly during middle age or at mid-range of the BP distribution $(140 \mathrm{~mm} \mathrm{Hg})$, others experience little rise at all. The effect of environment upon BP is often claimed to increase with length of exposure to environmental stress [9]. A result of increased stress upon a segment of a population, then, might be the accentuation of differences in BP among marker phenotypes closely linked to loci affecting ability to cope with environmental stress. This genotype by environment interaction should be reflected in the failure for the mean $\mathrm{BP}$ of the phenotypes to be homogeneous between a random sample from the population and a subsample exposed to excessive stress. Our results are consistent with such a genotype by environment interaction in which the heritable component of BP is expressed when and if high risk genotypes are exposed to the excessive environmental stress which we presume to precede life crises such as emigration and mortality. The genotype effect identified by the markers studied here would not be exposed by the typical study design used in human populations. Since evidence for a statistically significant genotype effect alone was observed only in the Kell emigrant-die marker case and is, of course, confounded by interaction, it is proposed that recent failure of other investigators to reveal significant and reproducible marker phenotype associations with BP levels $[5,35,36]$ results from their failure to consider interactions with environment in such associations.

Our findings imply that social indicators of emotional stress and the dosage of two marker alleles might provide a focus for prophylactic control of hypertension. Our methods could be used to identify individuals of high and low en- 
vironmental and biological risk for other health consequences for which such control is feasible. It will be of interest, for example, to determine if the geneticenvironment interactions which we have identified in the variation of $\mathrm{BP}$ are also associated with other dimensions of cardiovascular health.

Acknowledgements--This study was supported by U.S. Atomic Energy Commission Contract AT (11-1)1552, U.S.P.H.S. Program Project Grant H-6378 to the Cardiovascular Research Center, University of Michigan, Ann Arbor, MI and NIH Post-doctoral Research Grant 1 F22 HD04089-01. Portions of this paper were presented at the annual meeting of the American Association of Physical Anthropologists, Denver, 1975.

\section{REFERENCES}

1. Feldman JG, Ibrahim MA, Sultz HA: Differential filial aggregation of coronary risk factors. Hum Biol 45: 541-552, 1973

2. Oldham PD, Pickering G, Fraser Roberts JA, Sowry GSC: The nature of essential hypertension. Lancet 1: $1085-1093,1960$

3. Pickering GW: The role of the genetic factor in hypertension. Acta Med Scand: suppl. 312, 1954

4. Dahl LK, Heine M, Tassinari L: Effects of chronic excess salt ingestion: Evidence that genetic factors play an important role in susceptibility to experimental hypertension. J Exp Med 115: 1173,1962

5. Nance WE, Krieger H, Azevedo E, Mi MP: Human blood pressure and the ABO blood group system. Hum Biol 37: 238-244, 1965

6. Dahl LK, Knudsen KD, Iwai J: Genetic influence of the kidney in hypertension-prone rats, in Hypertensive Mechanisms. R. Reader (Ed.) American Heart Association, monograph 32, Circulation Research 26, 27, suppl 2(II), 1970, p. 277

7. Rapp JP, Knudsen KD, Iwai J, Dahl LK: Genetic control of blood pressure and corticosteroid production in rats. Circ Res 32, 33 suppl 1: I-139, 1973

8. Murphy EA: Genetics in hypertension. Circ Res 32, 33 suppl 1: I-129, 1973

9. Pickering GW: High Blood Pressure. London: J. \& A. Churchill, 1968

10. Strehler BL: Time, Cells and Aging. Academic Press, New York, 1962

11. Scotch NA, Geiger HJ: The epidemiology of essential hypertension: A review with special attention to psychologic and sociocultural factors-2. Psychologic and sociocultural factors in etiology. J Chron Dis 16: 1183-1213, 1963

12. Stamler J, Berkson DM, Linberg HA, Miller WA, Stamler R, Collette P: Socioeconomic factors in the epidemiology of hypertensive disease, in The Epidemiology of Hypertension. J Stamler, R Stamler, TN Pullman (Eds). New York: Grune \& Stratton, 1967

13. Kannel WB, Dawber TR, Kagan A, Revotskie N, Stokes J: Factors of risk in the development of coronary heart disease - six year follow-up experience. Ann Intern Med 55: 33-50, 1961

14. Wardell WI, Hyman M, Bahnson CB: Stress and coronary heart disease in three field studies. J Chron Dis 17: 73-84, 1964

15. Smith DG, Sing CF: Sample bias in longitudinal genetic-epidemiologic analyses. Hum Biol 48 . 529-539, 1976

16. Smith DG, Sing CF: The effect of sample attrition on the frequency distribution of blood pressure and phenotypes representing a natural unselected community: Tecumseh, Michigan. Am J Phys Anthropol 44: 139-149, 1976

17. Bancroft TA: Topics in Intermediate Statistical Methods-1. Ames, Iowa: The Iowa State University Press, 1968

18. Cockerham CC: An extension of the concept of partitioning hereditary variance for analysis of covariances among relatives when epistasis is present. Genetics 39:859-882, 1954

19. Bach FH: Genetic control of histocompatibility antigens. Am J Hum Genet 25: 208-212, 1973

20. Ritzmann SE: HLA patterns and disease associations. J Am Med Assoc 236: 2305-2309, 1976

21. Lowenstein $\mathbf{F W}$ : Blood pressure in relation to age and sex in the tropics and subtropics. Lancet 1: 389-392, 1961

22. Scotch NA: Sociocultural factors in the epidemiology of Zulu hypertension. Am J Publ Hlth 53: 1205-1213, 1963

23. Shaper AG: Blood pressure studies in East Africa, in: The Epidemiology of Hypertension. Stamler J, Stamler R, Pullman TN (Eds) New York: Grune \& Stratton, 1967

24. Cruz-Coke R: Environmental influences and arterial blood pressure. Lancet 2: 885-886, 1960 
25. Harburg E, Schull WJ, Erfurt JC, Schork MA: A family set method for estimating heredity and stress-I. A pilot survey of blood pressure among Negroes in high and low stress areas, Detroit, 1966-1967. J Chron Dis 23: 69-81, 1970

26. Cruz-Coke R, Etcheverry P, Nagel R: Influence of migration on blood pressure of Easter Islanders. Lancet 1: 697-699, 1964

27. Brod J: Hemodynamics and emotional stress, in: Psychosomatics in Essential Hypertension. (Bibl Psychiat 144) Koster M, Musaph H, Visser P (Eds), Basel: Karger, 1970

28. Levi L: Emotional stress and sympatho-adrenomedullary and related physiological reactions with particular reference to cardiovascular pathology, in: Psychosomatics in Essential Hypertension (Bibl Psychiat 144), Koster M, Musaph H, Visser P (Eds) Basel: Karger, 1970

29. Koster M: Patterns of hypertension, in: Psychosomatics in Essential Hypertension (Bibl Psychiat 144), Koster M, Musaph H, Visser P (Eds), Basel: Karger, 1970

30. Weiner H: Psychosomatic research in essential hypertension: Retrospect and prospect, in: Psychosomatics in Essential Hypertension. (Bibl Psychiat 144), Koster M, Musaph H, Visser P (Eds), Basel: Karger, 1970

31. Ostfeld AM, Shekelle RB; Psychological variables and blood pressure, in: The Epidemiology of Hypertension. Stamler J, Stamler R, Pullman TN (Eds), New York: Grune \& Stratton, 1967

32. McDonough J, Garrison G, Hames C: Blood pressure and hypertensive disease among Negroes and Whites in Evans County, Georgia, in: The Epidemiology of Hypertension. Stamler J, Stamler R, Pullman TN (Eds), New York: Grune \& Stratton, 1967

33. Frohlich E, Tarazi R, Dustan H: Reexamination of the hemodynamics of hypertension. Am J Med Sci 257: 9-23, 1969

34. Gutmann M, Benson $\mathrm{H}$ : Interaction of environmental factors and systemic arterial blood pressure: A review. Medicine 50: 543-553, 1971

35. Fraser GR, Volkers WS, Bernini LF, Degreve WB, Van Loghem E, Merra Khan P, Nijenhuis LE, Veltkamp JJ, Vogel GP, Went LN: A search for associations between genetical polymorphic systems and physical, biochemical and haematological variables. Hum Hered 24: 424-434, 1974

36. Cruz-Coke R, Nagel R, Etcheverry R: Effects of locus $\mathrm{NN}$ on diastolic blood pressure in a human population. Ann Hum Genet 38: 39-48, 1964 